Metacognition and motivation as predictors for mathematics performance of Belgian elementary school children.

Annemie Desoete ${ }^{12}$, Elke Baten ${ }^{1}$ Vera Vercaemst ${ }^{3}$, Ann De Busschere ${ }^{3}$, Myriam Baudonck ${ }^{3}$, Jennis Vanhaeke ${ }^{4}$.

${ }^{1}$ Department of Experimental Clinical and Health Psychology, Ghent University, Belgium 2 Arteveldehogeschool, Ghent, Belgium

3 Centre for Rehabilitation Overleie, Kortrijk, Belgium

4 Libraro Bruges, Belgium

Article-related correspondence may be addressed to Annemie Desoete, Department of

Experimental Clinical and Health Psychology, Ghent University, Henri Dunantlaan 2, B-9000

Ghent, Belgium. Electronic mail can be sent to Annemie.Desoete@UGent.be. 
Metacognition and motivation as predictors for mathematics performance of Belgian elementary school children.

Abstract

In this paper, we investigate the role of metacognitive postdiction skills, intrinsic motivation and prior proficiency in mathematics as Propensity factors within the Opportunity-Propensity (O-P) model of learning. We tested Belgian children from Grade 1 till 6 in January and June. The study revealed overlapping yet different predictors for mathematical accuracy and fluency, which led us to the practical recommendation for teachers to pay attention to both aspects of mathematics. The metacognitive postdiction skills of children were related to accuracy in mathematics during the whole elementary school period. In addition, we observed that children evaluated their own performance as worse when they were slower in Grades 3 and 4. Intrinsic motivation was related to accuracy but not to fluency in Grade 3. Especially prior mathematical accuracy mattered as a propensity factor. More than half of the variance in accuracy and less than one fifth of the variance in fluency in January predicted the performances of children for mathematics in June, a finding that highlights the importance of longitudinal designs including students' prior mathematical accuracy' as well. Finally, we observed that poor mathematics performers are less intrinsically motivated, and less metacognitively accurate. Moreover, they overestimate their performances more often than well-performing peers in all grades, stressing the importance of paying attention to these aspects in mathematics education.

Keywords: metacognitive postdiction, metacognitive accuracy, intrinsic motivation, prior knowledge, mathematical accuracy, mathematical fluency, overestimation 


\section{Metacognition and motivation as predictors for mathematics performance of Belgian elementary school children.}

\section{Introduction}

Already at the very start of the first year of formal education, individual differences exist amongst children in terms of mathematical proficiency (Claessens et al. 2009; Claessens and Engel 2013). As education continues, differences amongst children live on. Moreover, in Belgium in recent years, the overall performance on mathematics tests has decreased, and more than half of the children continue to have problems in solving fractions and percentages at the end of elementary school (Aesaert and Denis 2018). The current teaching practices seem inadequate to resolve these difficulties, which results in continuing problems during the secondary school years and even in adulthood. These inadequate teaching practices might have a serious impact, since Duncan and Magnuson (2009) revealed that children who kept scoring low in mathematics during elementary school were found to have 13 percent less chance of graduating from high school and 29 percent less chance of starting college education compared to typically developing peers. Individuals with poor mathematical skills are therefore prone to having an elevated risk of unemployment and low academic selfesteem. A lack of mathematical literacy has also been found to affect people's ability to gain full-time employment, a finding that predicts restricted employment options and low-paying jobs (Dowker 2005).

Adequate mathematical problem solving relies on several interrelated mathematical skills (Siemann and Petermann 2018). Accurate calculation skills are required to complete mathematical tasks in a number problem format (e.g., $39+60=\ldots$ ) or in short sentences (e.g., 6 more than 48 is ...). Additionally, mathematical competence relies on the fluency to determine arithmetic facts (e.g., 16 :divided by $4=\ldots$.). Therefore, skill in mathematics is considered to be componential in nature (Dowker 2015). In addition, some authors propose 
that mathematical learning difficulties might also represent heterogeneous problems (Henik et al. 2015). Some children seem to be characterized by a delay in the accuracy or acquisition of calculation procedures (Pieters et al. 2015). In contrast, other children are marked by a lack of fact retrieval fluency (Pieters et al. 2015).

However, not only mathematical accuracy and mathematical fluency subskills seem to be involved in the completion of mathematical tasks. The Opportunity-Propensity model supplies us with a framework to reflect on individual differences in mathematical abilities from a broader perspective. Byrnes and Miller (2007) have distinguished Opportunity (O) and Propensity $(\mathrm{P})$ factors to explain variance in mathematical development. Propensity factors are variables that enable people (e.g., prior knowledge, metacognition) and/or make them willing (e.g., motivation) to learn. Studies have demonstrated that the effects of the model are reciprocal (Guay et al. 2003; Seaton et al. 2015). Opportunity factors include contexts and variables that expose children to learning content (e.g., classroom instruction, home and school context). Antecedent variables explain why some people are exposed to fuller opportunity contexts and have stronger propensities for learning than others (Baten and Desoete, 2018; Baten et al. 2017; Byrnes and Miller, 2007, 2016; Wang and Byrnes, 2013). To conclude, the O-P model observes cognitive (metacognition and prior knowledge) and motivational Propensity factors. In the following section a definition and short overview of these constructs is presented to explain differences in the mathematics performance of different children.

\subsection{Cognitive propensity predictors for mathematics performance}

Studies have demonstrated that 'cognitive' propensity predictors may influence academic performance (Byrnes and Miller 2007; Carr and Jessup 1995; Wang et al. 2013). In some studies, students' prior domain knowledge and general mathematics proficiency, as cognitive 
propensity predictors, influenced their later academic performance (Arefi et al. 2014; Lin and Zabrucky 1998; Nietfeld and Schraw 2002).

In addition, 'metacognition' is one of the promising contemporary research fields in education. It has been suggested that metacognition is relevant and efficient for instructional design in the domain of mathematics (Baten et al., 2017; Carr et al., 1994; Desoete et al., 2013; Lucangeli et al., 1998). The concept has been introduced to describe and explain how people gain control over their learning and thinking, particularly in the case of cognitive failures and difficulties they meet when dealing with information processing and mathematical tasks (Efklides and Sideridis 2009; Flavell 1976; 1979; 1987). Most people agree that metacognition refers to ‘cognition about cognition' (Furnes and Norman 2015) or to self-referential confidence, check and balance (Fleming et al. 2012; Nelson 1996). It has been suggested that metacognition may consist of effective subskills needed for proficient mathematical problem solving (Desoete 2007; Lucangeli et al. 1998).

Although the metacognitive concept is over 40 years old, researchers keep using different definitions for this construct (Baten et al. 2017; Brown 1987; Gascoine et al. 2017; Perfect and Schwartz 2002; Tarricone 2011). In addition, different evaluators (Ozcan 2014) and techniques to assess metacognition (Desoete 2008; Fleming and Lau, 2014; Sperling et al. 2002; Veenman 2011) render studies difficult to compare. A methodical review of the assessment of metacognition for children aged 4-16 years over a 20-year period (1992-2012) revealed that self-report measures (including questionnaires, surveys and tests) comprise $61 \%$ of the included tools (Gascoine et al. 2017). In addition, not merely the choice of the method, but also the choice of the techniques and the included variables might matter. Generally, metacognition distinguishes two central components, namely metacognitive knowledge and metacognitive skills. A study by Özsoy (2011) revealed that $42 \%$ of the total variance of mathematics achievement in Grade 5 may be explained by a combination of metacognitive knowledge and 
skills.

Metacognitive knowledge has been described as the (declarative) knowledge and deeper understanding of cognitive processes and products (Flavell 1976). According to Efklides (2008), metacognitive knowledge encompasses information regarding persons, as well as information about tasks, strategies, and goals. In addition, metacognitive skills refer to the deliberate use of strategies (procedural knowledge) in order to control cognition (Efklides 2008). Schneider and Artelt (2010) demonstrated that metacognitive knowledge and mathematics shared about 15-20\% of common variance in fifth grade (9-10-year-old) children.

Metacognitive skills have been related to mathematics (Desoete 2007; Lucangeli and Cornoldi 1997; Özsoy 2011; Veenman et al. 2006). These skills seem especially involved in new and effortful mathematical tasks (Carr et al. 1994; Vermeer et al. 2000; Verschaffel 1999). A combination of metacognitive prediction and evaluation skills distinguish children with mathematics learning disabilities from below-average performing peers and average performers from experts (Desoete et al. 2001; Desoete and Roeyers 2002). Evaluating one's performance (or metacognitive postdiction) is done after completing the mathematical tasks .

Metacognitive postdiction skills seem to improve with age (Desoete and Roeyers 2006), task experience (Bol and Hacker 2012; Hacker et al. 2000; Stolp and Zabrucky 2009) and towards the end of a semester (Lin-Agler et al. 2004; Stolp and Zabrucky 2009). The accuracy of metacognitive postdiction skills can be assessed by means of self-reports, such as 'Judgments of Learning (JOL)' after task performance (Bol and Hacker 2012; Efklides 2008; Schneider and Löffler 2016).

Poor JOL might endanger appropriate control and monitoring decisions (Efklides 2008; Kruger and Dunning 1999) during and after task performance, entailing underachievement in mathematics. If children cannot accurately evaluate (postdict) their mathematical performance 
during the test, decisions about how to focus their efforts, given the time to complete mathematical tasks, might not be efficient. JOLs have been proven to be especially useful in limited time situations, in order to maximize overall performance (Townsend and Heit 2011). In addition, these children might not evaluate themselves correctly if their skills required to complete mathematical tasks would benefit from the allocation of additional study time and restudying, resulting in lower or non-optimal future mathematical test performances. Good JOL might lead to superior test performance, as compared with peers with less developed postdiction skills. Poor postdictions might obstruct later mathematics performance. Metacognitive accuracy in postdiction might therefor be used as a relevant indicator of metacognition and (later) mathematics performance.

Several studies have suggested small correlations between metacognitive postdiction skills, or confidence rates, and mathematics performance scores (Hacker et al. 2000; Lin et al. 2001; Lin and Zabrucky 1998), and an overall 'overconfidence' (or children evaluating themselves to have higher mathematics scores than they actually received) stronger than in other academic subjects such as in biology and literature (Erickson and Heit 2015; Stolp and Zabrucky 2009). Kruger and Dunning (1999) and Kruger (2002) explained the poor postdiction skills of low achieving children by the fact that the knowledge that underlies taking a test (e.g., in mathematics) is also the knowledge that underlies the ability to evaluate one's performance after the task. Therefore, students who performed poorly might fail to recalibrate their postdictions (Kruger 2002; Kruger and Dunning 1999; Stolp and Zabrucky 2009; Vanderswalmen et al. 2010).

Up to now most studies have used a cross-sectional design focusing on isolated predictors. However, it might be important to study combined propensity predictors. In this study 'prior knowledge' as well as 'accuracy' of postdictions has been investigated, with children who manifest poor, moderate and good mathematical skills. 


\subsection{Motivation as propensity predictor for mathematics performance}

Motivation is the commitment to oneself to learn (Efklides 2001, 2006; Vansteenkiste et al. 2009) and the desire to engage in things, in this case, to solve mathematical exercises. Carr and colleagues (1994) found significant relations, in second graders, between metacognitive knowledge and motivation. High scores regarding both characteristics contribute to the increase in mathematics performance.

Children may have different types of motivation to complete mathematical tasks. (Borkowski and Thorpe 1994; Efklides 2006; Orsini et al. 2015). The Self-Determination Theory (Deci et al. 1989; Deci and Ryan 1985; Orsini et al. 2015; Ryan and Deci 2017), one of the leading theories in motivational psychology, claims that there is a difference between internal or autonomous and external or controlled motivation. The more 'autonomous' the motivation, the better children will learn (Vansteenkiste et al 2009). Children might study mathematics because, if they pass a test, their teacher will give them a present. This external motivation source is defined as 'controlled' motivation. In contrast, children may also study mathematics because of the personal relevance for a later academic career or due to feelings of pleasure or passion. Children are 'autonomously' motivated when their motivation to perform is internal (Gagné and Deci 2005; Vansteenkiste et al. 2009). 'Liking a task' refers to feelings of pleasure and passion or to 'internal' and autonomous motivation.

The Program for International Student Assessment (PISA) data revealed and clarified, for fifteen-year-old German students, variances between 1 and 29 percent for several motivational factors in the mathematics domain (Kriegbaum et al. 2015). In the United Kingdom, motivation also predicted achievement in mathematics better than general intelligence (Spinath et al. 2006). However, this was not the case for Chinese primary school pupils, for whom only marginally significant predictions were reported. Cultural differences 
in opportunities (Europe vs. China) have been postulated (Lu et al. 2011) to explain this lack of consistency throughout the PISA findings.

\subsection{Aims of the study}

Several propensity variables might predict mathematical performance. Not only cognitive, but also motivational propensities are considered important.

There were three major aims in this study: Firstly, the present study investigated ('concurrently') whether the same propensity predictors (prior knowledge, metacognitive postdiction and intrinsic motivation) are related to mathematical accuracy and fluency. In addition, in line with Deary and colleagues (2000) we analysed whether these propensity predictors are equally important in all grades, since the age of children might influence our findings.

Secondly, the importance of the propensities has been studied 'prospectively' within a longitudinal perspective. Prior mathematics knowledge, metacognitive postdiction and intrinsic motivation, assessed in January 2017, were used as predictors of mathematical accuracy and fluency in June 2017.

Finally, differences between performance groups (poor, moderate and good mathematical problem solvers) concerning the same propensity factors were investigated.

We put forward the hypothesis that better postdiction skills (Desoete and Roeyers 2006) and higher levels of autonomous motivation (Taylor et al. 2014) would positively predict mathematical abilities. However, it remained unclear whether these propensities would affect accuracy or fluency, or both. By examining the (differential) effects on both mathematical aspects, this study took into account the componential nature of mathematics (Cohen et al.2015; Dowker 2015; Pieters et al. 2015), an expansion of previous designs. In addition, because it examined both concurrent relations (in January of each grade), as well as 
prospective predictions (from January each grade to June of the same grade), the design of the current study may be considered unique.

\section{Method}

\subsection{Participants}

Six cohorts (671 first graders, 401 second graders, 481 third graders, 482 fourth graders, 468 fifth graders and 339 sixth graders) of children ( $n=2842 ; 52 \%$ boys $)$ participated in the crosssectional part of this study, and Grade 1 till 6 students were tested in January 2017. All children were invited to be tested again in June of the same school year, but only 1903 children agreed to participate in this follow-up, and were tested twice (in January and in June of the same year). Children that received a score equal to or lower than $Z=-1$ (below the $16^{\text {th }}$ percentile) in January were included as 'poor performers'. Children with a score equal to or higher than $Z=+1$ (above the $84^{\text {th }}$ percentile) were included as 'good performers'. Children with a total mathematics score between pc 16 $(Z>-1)$ and $84(Z<+1)$ were included as 'average performers'.

\subsection{Instruments}

Mathematical performance was tested (in January and June) through a computerized test (Baudonck et al. 2006).

More specifically, mathematical accuracy was assessed through calculating the number of correct answers for mental computation (e.g., $129+879=$ =) and number knowledge (e.g., add three tens to 61 and you have _), which resulted in a total accuracy score. Good accuracy resulted in a high score on this test (or in more exercises solved correctly). There was a significant correlation between the accuracy on this test and a regular test used by the government, with correlations varying from .59 to .65 . 
We determined mathematical fluency based on the time children spent completing the exercises. The lower this score, the less time spent on the tasks, and hence, the better the fluency. Cronbach's alpha for accuracy varied from .73 to .93 .

Metacognition was assessed (in January and in June) through computerized self-reports. Postdictions were tested asking children to evaluate their mathematics performance after the tasks.

In addition, the accuracy of postdiction was calculated based on the comparison of the postdiction and the real performance scores. A positive score referred to self-underestimation. A negative score referred to self-overestimation. The nearer to zero, the more correct the student's postdiction.

Motivation was measured in January and June through children answering the question 'Did you like these exercises?' on a 5-point scale, after they had completed all exercises. Higher scores corresponded to more intrinsic (and autonomous) motivation for mathematics, whereas lower scores corresponded to less intrinsic motivation.

Although intrinsic motivation was assessed by means of only one question, students and teachers were able to handle the question well, and the reasons they gave for their answers in a previous study all referred to intrinsic motivation (see Desoete and Roeyers 2006).

\subsection{Statistical analyses}

Since the assumptions for parametric testing were met, linear regressions and a Multivariate Analyses of Variance (MANOVA) were carried out.

To answer the first research question, two linear regression analyses were performed. The first regression examined mathematical fluency, metacognitive postdiction and intrinsic motivation as propensity predictors (assessed in January) for mathematical accuracy (assessed in January) as outcome. The second regression was carried out for mathematical accuracy, 
metacognitive postdiction and intrinsic motivation as propensity predictors, and mathematical fluency (also assessed in January of each grade) as outcome variable.

To answer the second research question, a linear regression analysis was performed with previous knowledge (assessed in January), metacognitive postdiction (assessed in January) and intrinsic motivation (assessed in January) to predict mathematical accuracy (assessed in June of the same year). To predict mathematical fluency (in June) we went through the same procedure(s).

Finally, to answer the last research question, a MANOVA was carried out on the (metacognitive) postdiction 'accuracy' scores (or the comparison of the metacognitive postdiction and real mathematical performance in January and June), and on the intrinsic motivation scores (in January and June) of children with poor, average and good mathematics skills.

\section{Results}

\subsection{Research Question 1: Concurrent relationships}

For the concurrent relationships between mathematical accuracy as outcome and fluency, metacognition (postdiction) and intrinsic motivation as predictors, see Table 1 .

Table 1. Concurrent predictors of accuracy in mathematics in January in Grades 1 to 6.

$\begin{array}{lllll}B & S . E & \beta & T\end{array}$

Grade $1 \quad\left(R^{2}=.06 ;(3,635)=13.58, p<.001\right)$,

$\begin{array}{lccccc}\text { Fluency January } & 0.00 & .00 & -.13 & -3.22 & .001 * \\ \text { Postdiction January } & 1.04 & .19 & .22 & 5.55 & .000^{*} \\ \text { Motivation January } & -0.12 & .25 & -.02 & -0.50 & .617\end{array}$

Grade $2 \quad\left(R^{2}=.04 ; F(3,388)=5.75 ; p=.001\right)$

$\begin{array}{llllll}\text { Fluency January } & 0.03 & .00 & .10 & 2.05 & .041\end{array}$


Postdiction January

Motivation January
$0.42 \quad .16$

$0.46 \quad .24$

Grade $3 \quad\left(R^{2}=.09 ; F(3,457)=14.73 ; p<.001\right)$
$0.00 \quad .00$

$0.77 \quad .19$

Postdiction January

Motivation January

$0.84 \quad .29$

Fluency January

.14

$2.667 \quad .008^{*}$

1.91

.057

.17

$3.82 \quad .000^{*}$

$3.99 \quad .000 *$

$2.95 \quad .003 *$

Grade $4 \quad\left(R^{2}=.13 ; F(3,446)=23.41 ; p<.001\right)$

Fluency January

$0.00 \quad .00$

.18

$4.13 \quad .000^{*}$

Postdiction January

$1.18 \quad .18$

.29

$6.48 \quad .000 *$

Motivation January

$0.58 \quad .26$

.09

2.19

.029

Grade $5 \quad\left(R^{2}=.12 ; F(3,456)=21.11 ; p<.001\right)$

Fluency January

$0.00 \quad .00$

.17

3.82

$.000^{*}$

Postdiction January

$1.10 \quad .18$

.28

6.29

$.000^{*}$

Motivation January

$0.34 \quad .27$

.06

1.26

.207

Grade $6 \quad\left(R^{2}=.16 ; F(3,321)=20.91 ; p<.001\right)$

Fluency January

Postdiction January

Motivation January
$-0.00 \quad .00$

$1.68 \quad .23$

$0.06 \quad .29$
$-.07$

$-1.37$

.173

.39

7.34

$.000 *$

$* p \leq .01$

Although $R^{2}$ varies from .03 (in Grade 2 about 4\% explained variance) to .16 (in Grade 6

about $16 \%$ explained variance, see Table 1), metacognitive postdiction skills are significant $(p \leq .01)$ concurrent predictors of mathematical accuracy in all grades. Moreover, in Grade 3 motivation as well is significantly $(p \leq .01)$ related to accuracy in mathematics. Finally, the mathematical fluency of children in Grade $1,3,4$ and 5 is significantly $(p \leq .01)$ related to their mathematical accuracy. At the start of elementary school (Grade 1) the more slowly 
children work, the more accurate they are. In the middle of elementary school (Grades 3 to 5) high fluency is related to high accuracy in mathematics.

The second regression (see Table 2) on mathematical fluency revealed that metacognitive postdiction skills are significantly related to mathematical fluency in mathematics in Grades 3 and $4(p \leq .01)$.

Table 2. Concurrent predictors of fluency in mathematics in January in Grades 1 to 6.

$\begin{array}{lllll}B & \text { S.E } & \beta & t & p\end{array}$

Grade $1 \quad\left(R^{2}=.02 ; \quad(3,638)=3.95, p=.008\right)$,

$\begin{array}{lccccc}\text { Accuracy January } & -3.32 & 1.03 & -.13 & -3.22 & .001 * \\ \text { Postdiction January } & 7.51 & 5.04 & .06 & 1.49 & .137 \\ \text { Motivation January } & -7.24 & 6.55 & -.04 & -1.11 & .269\end{array}$

Grade $2 \quad\left(R^{2}=.02 ; F(3,388)=2.77 ; p=.041\right)$

$\begin{array}{lccccc}\text { Accuracy January } & 4.11 & 2.00 & .10 & 2.05 & .041 \\ \text { Postdiction January } & -13.44 & 6.33 & -.11 & -2.12 & .034 \\ \text { Motivation January } & 8.76 & 9.59 & .05 & 0.91 & .362\end{array}$

Grade $3 \quad\left(R^{2}=.04 ; F(3,460)=6.34 ; p<.001\right)$

$\begin{array}{lccccc}\text { Accuracy January } & 6.95 & 1.82 & .18 & 3.81 & .000^{*} \\ \text { Postdiction January } & -20.74 & 7.73 & -.13 & -2.68 & .008^{*} \\ \text { Motivation January } & 3.55 & 11.41 & .02 & 0.31 & .756\end{array}$

Grade $4 \quad\left(R^{2}=.04 ; F(3,462)=6.44 ; p<.001\right)$

Accuracy January

$\begin{array}{lllll}9.13 & 2.21 & .19 & 4.13 & .000 *\end{array}$

Postdiction January

$\begin{array}{lllll}-23.22 & 9.08 & -13 & -2.56 & .011^{*}\end{array}$

Motivation January

$\begin{array}{lllll}-3.09 & 12.76 & -.01 & -0.24 & .808\end{array}$

Grade $5 \quad\left(R^{2}=.04 ; F(3,456)=5.33 ; p=.001\right)$

Accuracy January

$8.25 \quad 2.16$

.19

$3.824 \quad .000^{*}$ 
Postdiction January

Motivation January
$-0.5$

$0.92 \quad 12.83$
$-.00$

$-0.06$

.00

0.07

Grade $6 \quad\left(R^{2}=.02 ; F(3,321)=2.28 ; p=.079\right)$

$\begin{array}{llllll}\text { Accuracy January } & -6.23 & 4.56 & -.08 & -1.37 & .173 \\ \text { Postdiction January } & -21.32 & 20.22 & -.07 & -1.05 & .292 \\ \text { Motivation January } & -22.49 & 23.40 & -.06 & -0.96 & .337\end{array}$

$* p \leq .01$

Children estimate their own performances after the task lower when they are slower.

However, the intrinsic motivation of children is not significantly related to mathematical fluency in elementary school. Finally, mathematical accuracy is significantly related to mathematical fluency in Grades 1, 3, 4 and $5(p \leq .01)$.

\subsection{Research Question 2: Prospective relationships}

Regressions analyses were performed on mathematics, postdiction, and motivation scores as propensity factors (all assessed in January), to predict mathematics in June of each grade. (See the overview in Table 3.)

Table 3. Prospective predictors (assessed in January) of mathematics (assessed in June) in Grades 1 to 6

\begin{tabular}{llccccc}
\hline Outcome (June) Predictors (January) & $B$ & $S . E$. & $\beta$ & $t$ & $p$ \\
\hline Grade 1 Accuracy & Mathematical accuracy & 0.70 & .02 & .73 & 43.08 & $.000^{*}$ \\
$R^{2}=.54 ; p<.001^{*}$ & Mathematical fluency & -0.00 & .00 & -.00 & -0.21 & .833 \\
& Metacognitive postdiction & -0.06 & .08 & -.01 & -0.77 & .440 \\
& Intrinsic motivation & 0.21 & .11 & .03 & 1.91 & .056 \\
\cline { 2 - 6 } & Mathematical accuracy & -4.37 & 0.84 & -.12 & -5.19 & $.000^{*}$ \\
$R^{2}=.14 ; p<.001 *$ & Mathematical fluency & 0.34 & 0.02 & .03 & 14.57 & $.000 *$
\end{tabular}




\begin{tabular}{|c|c|c|c|c|c|c|}
\hline & Metacognitive postdiction & 1.69 & 4.22 & .01 & 0.40 & .689 \\
\hline & Intrinsic motivation & -9.69 & 5.74 & -.04 & -1.69 & .091 \\
\hline Grade 2 Accuracy & Mathematical accuracy & 0.85 & 0.04 & .76 & 20.18 & $.000 *$ \\
\hline \multirow[t]{3}{*}{$R^{2}=.57 ; p<.001^{*}$} & Mathematical fluency & -0.00 & 0.00 & -.09 & -2.330 & .020 \\
\hline & Metacognitive postdiction & -0.18 & 0.13 & -.05 & -1.37 & .171 \\
\hline & Intrinsic motivation & 0.12 & 0.19 & .02 & 0.63 & .532 \\
\hline Grade 2 Fluency & Mathematical accuracy & -12.03 & 2.06 & -.30 & -5.839 & $.000^{*}$ \\
\hline \multirow[t]{3}{*}{$R^{2}=.19 ; p<.001^{*}$} & Mathematical fluency & 0.28 & 0.05 & .29 & 5.72 & $.000^{*}$ \\
\hline & Metacogntive postdiction & -7.65 & 6.30 & -.07 & -1.21 & .226 \\
\hline & Intrinsic motivation & -16.25 & 9.16 & -.09 & -1.77 & .077 \\
\hline Grade 3 Accuracy & Mathematical accuracy & 0.88 & 0.04 & .83 & 24.72 & $000^{*}$ \\
\hline \multirow[t]{3}{*}{$R^{2}=.69 ; p<.001 *$} & Mathematical fluency & -0.00 & 0.00 & -.09 & -2.72 & $.007 *$ \\
\hline & Metacognitive postdiction & -0.06 & 0.15 & -.01 & -0.41 & .683 \\
\hline & Intrinsic motivation & 0.38 & 0.21 & .06 & 1.68 & .076 \\
\hline Grade 3 Fluency & Mathematical accuracy & -3.01 & 2.12 & -.08 & -1.42 & .158 \\
\hline \multirow[t]{3}{*}{$R^{2}=.14 ; p<.001 *$} & Mathematical fluency & 0.38 & 0.06 & .37 & 6.87 & $.000 *$ \\
\hline & Metacognitive postdiction & 1.73 & 8.95 & .01 & 0.19 & .847 \\
\hline & Intrinsic motivation & 16.16 & 12.61 & .07 & 1.28 & .201 \\
\hline Grade 4 Accuracy & Mathematical accuracy & 0.81 & 0.04 & .79 & 22.44 & $.000^{*}$ \\
\hline \multirow[t]{3}{*}{$R^{2}=.64 ; p<.001 *$} & Mathematical fluency & -0.00 & 0.00 & -.14 & -4.31 & $.000 *$ \\
\hline & Metacognitive postdiction & 0.23 & 0.16 & .05 & 1.43 & .158 \\
\hline & Intrinsic motivation & 0.07 & 0.21 & .01 & 0.31 & .758 \\
\hline Grade 4 Fluency & Mathematical accuracy & -10.06 & 3.94 & -.14 & -2.55 & $.011^{*}$ \\
\hline \multirow[t]{2}{*}{$R^{2}=.07 ; p<.001^{*}$} & Mathematical fluency & 0.35 & 0.08 & .23 & 4.36 & $.000 *$ \\
\hline & Metacognitive postdiction & 11.83 & 17.27 & .04 & 0.68 & .494 \\
\hline
\end{tabular}




\begin{tabular}{|c|c|c|c|c|c|c|}
\hline & Intrinsic motivation & -24.36 & 23.25 & -.06 & -1.05 & .295 \\
\hline Grade 5 Accuracy & Mathematical accuracy & 0.83 & 0.05 & .75 & 18.32 & $.000^{*}$ \\
\hline \multirow[t]{3}{*}{$R^{2}=.55 ; p<.001^{*}$} & Mathematical fluency & -0.00 & 0.00 & -.14 & -3.59 & $.000 *$ \\
\hline & Metacognitive postdiction & 0.17 & 0.16 & .04 & 1.06 & .288 \\
\hline & Intrinsic motivation & 0.04 & 0.23 & .01 & 0.17 & .868 \\
\hline Grade 5 Fluency & Mathematical accuracy & -6.97 & 2.79 & -.14 & -2.50 & $.013 *$ \\
\hline \multirow[t]{3}{*}{$R^{2}=.11 ; p<.001^{*}$} & Mathematical fluency & 0.33 & 0.05 & .34 & 6.22 & $.000 *$ \\
\hline & Metacognitive postdiction & 2.95 & 9.63 & .02 & 0.31 & .759 \\
\hline & Intrinsic motivation & 0.48 & 14.00 & .00 & 0.03 & .973 \\
\hline Grade 6 Accuracy & Mathematical accuracy & 0.85 & 0.05 & .77 & 17.83 & $.000 *$ \\
\hline \multirow[t]{3}{*}{$R^{2}=.65 ; p<.001 *$} & Mathematical fluency & 0.00 & 0.00 & .04 & 1.00 & .318 \\
\hline & Metacognitive postdiction & 0.34 & 0.22 & .07 & 1.60 & .110 \\
\hline & Intrinsic motivation & 0.19 & 0.24 & .03 & 0.81 & .423 \\
\hline Grade 6 Fluency & Mathematical accuracy & -8.79 & 3.05 & -.19 & -2.88 & $.004 *$ \\
\hline \multirow[t]{3}{*}{$R^{2}=.10 ; p<.001 *$} & Mathematical fluency & 0.17 & 0.05 & .23 & 3.56 & $.000 *$ \\
\hline & Metacognitive postdiction & -0.72 & 13.98 & -.00 & -0.05 & .959 \\
\hline & Intrinsic motivation & 0.86 & 15.34 & .00 & 0.06 & .955 \\
\hline
\end{tabular}

$* p \leq .01$

All prospective predictions are significant (see Table 3). There is an explained variance between 54\% (Grade 1) and 69\% (Grade 3) for mathematical accuracy, and between 7\% (Grade 4) and 19\% (Grade 2) for mathematical fluency. Hence, from a longitudinal perspective, accuracy and fluency at the end of the year might be significantly $(p \leq .01)$ predicted by the same constructs as 'propensity factors' six months before. In addition, mathematical accurarcy in January predicts mathematical fluency in June in Grades 1, 2, 4, 5 and 6, whereas mathematical fluency in January predicts mathematiacl accuracy in June in 
Grades 3, 4 and 5. However, from a longitudinal perspective, metacognitive postdiction skills and motivation as propensity factors did not significantly add to the prediction of mathematics six months later.

\subsection{Research Question 3: Poor, average and good performers}

To answer the next research question a MANOVA with group (poor, average, good performers) and Grade (1 to 6) as independent variables, and the accuracy of the metacognitive postdictions and motivation (in January and June) as dependent variables, was carried out.

The MANOVA is significant on the multivariate level for grade $(F(20,6242.84)=$ $\left.5.67 ; p<.001, \eta_{p=.02}^{2}\right)$ and group $\left(F(8,3764)=51.70 ; p<.001 ; \eta_{p}^{2}=.09\right)$. There is no significant Group x Grade interaction effect $\left(F(40,7138.18)=0.66 ; p=.953 ; \eta_{p}^{2}=.00\right)$. On the univariate level there are significant differences for postdiction accuracy in January $(F$ $\left.(17,1885)=17.62 ; p<.001 ; \eta_{p}^{2}=.14\right)$. and in June $\left(F(17,1885)=12.38 ; p<.001 ; \eta_{p}^{2}=.10\right)$. In addition, there are significant differences for motivation assessed in January $(F(17,1885)$ $\left.=6.44 ; p<.001 ; \eta_{p}^{2}=.06\right)$ and in June $\left(F(17,1885)=5.51 ; p<.001 ; \eta_{p}^{2}=.05\right)$. For $M$ and $S D$ of poor, average and good performers (see Table 4).

Table 4. Postdiction accuracy and intrinsic motivation among performance groups

\begin{tabular}{lcccccc}
\hline & \multicolumn{2}{c}{ Poor performers } & \multicolumn{2}{c}{ Average performers } & \multicolumn{2}{c}{ Good performers } \\
& $M$ & $S D$ & $M$ & $S D$ & $M$ & $S D$ \\
\hline Accuracy January & $-3.66^{c}$ & 2.86 & $-2.23^{b}$ & 2.35 & $-0.69^{a}$ & 1.77 \\
Motivation January & $2.23^{b}$ & 1.66 & $2.43^{a b}$ & 1.65 & $2.82^{a}$ & 1.76 \\
Accuracy June & $-2.73^{c}$ & 2.84 & $-1.63^{b}$ & 2.43 & $-0.28^{a}$ & 2.07
\end{tabular}


Motivation June

Note: ${ }^{\text {abc }}$ posthoc indexes $p \leq .01$, Accuracy $=$ metacognitive postdiction accuracy (a positive score refers to self-underestimation, the nearer to zero, the more accurate)

Poor mathematics performers ( ${ }^{\circ} b$ ' index in Table 4, pointing to significant differences $(p \leq .01)$ between groups) were less intrinsically motivated compared to good performers (' $a$, index in Table 4) in all grades. In addition, poor performers ( ${ }^{\circ}$ ' index in Table 4) overestimated their performance in January and in June more than average performers ( ${ }^{c} b$, index in Table 4) and good performers (' ${ }^{\prime}$ ' index in Table 4) in all grades. (For $M$ and $S D$ in the different grades see Table 5.)

Table 5. Metacognitive postdiction accuracy and intrinsic motivation in Grades 1 to 6

\begin{tabular}{lccccccc}
\hline & \multicolumn{2}{c}{ Grade 1 Grade 2} & \multicolumn{2}{c}{ Grade 3 Grade 4} & \multicolumn{2}{c}{ Grade 5 Grade 6} \\
$M$ & $M$ & $M$ & $M$ & $M$ & $M$ \\
& $S D$ & $S D$ & $S D$ & $S D$ & $S D$ & $S D$ \\
\hline Accuracy January & $-1.77^{b}$ & $-2.39^{a}$ & -2.12 & $-2.05^{a}$ & $-2.50^{a}$ & $-2.03^{a}$ \\
& $(2.81)$ & $(2.84)$ & $(2.63)$ & $(2.35)$ & $(2.06)$ & $(1.84)$ \\
Accuracy June & $-2.09^{b}$ & $-1.43^{a}$ & $-1.33^{a}$ & $-1.20^{a}$ & $-1.43^{a}$ & $-1.45^{a}$ \\
& $(3.24)$ & $(2.41)$ & $(2.19)$ & $(2.25)$ & $(2.23)$ & $(2.17)$ \\
\hline Motivation January & $3.03^{a}$ & 2.49 & 2.43 & 2.41 & $2.06^{b}$ & $2.09^{b}$ \\
& $(1.92)$ & $(1.82)$ & $(1.71)$ & $(1.58)$ & $(1.28)$ & $(1.31)$ \\
Motivation June & $2.45^{a}$ & 2.00 & 2.43 & 2.29 & 1.98 & $1.71^{b}$ \\
& $(1.82)$ & $(1.68)$ & $(1.71)$ & $(1.56)$ & $(1.25)$ & $(1.12)$
\end{tabular}

Note: ${ }^{\text {abc }}$ posthoc indexes $p \leq .01$ Accuracy $=$ metacognitive postdiction accuracy 
Since a negative metacognitive postdiction accuracy score (in Table 4) referred to selfoverestimation, all children in elementary school overestimated their mathematics proficiency. In Grade 1 the degree of this overestimation was higher in June than in January. In the other years it was the other way around. In addition, older children ( ${ }^{\circ} b$ ' index in Table 5) were less intrinsically motivated by the exercises than younger children (' $a$ ' index in Table 5).

\section{Discussion and conclusion}

This study revealed, in line with Dowker (2015) and Pieters and colleagues (2015), that mathematical accuracy and fluency seem to be overlapping yet different constructs. Is was not possible to use the same model for the description of concurrent and prospective relations with mathematical accuracy and fluency of elementary school children. Mathematical accuracy in January predicted fluency in June in almost all grades. Mathematical fluency in January predicted mathematical accuracy in June in Grades 3, 4 and 5. However the study also revealed that intrinsic motivation is related to mathematical accuracy yet not to mathematical fluency.

Within the Opportunity Propensity (O-P) model, metacognitive postdiction skills were related concurrently to mathematical accuracy in all grades (Grades 1-6) and to mathematics fluency in Grades 3 and 4. This finding demonstrates that evaluating one's performance immediately after the task is related to mathematical accuracy during the whole elementary school period. In addition, metacognitive postdiction is related to mathematical fluency in all grades where multiplication tables (Grade 3-4) are to be remembered, stored or retrieved from long term memory. This result is in line with postdiction (JOL) being especially useful, with a limited time, in order to maximize overall performance (Townsend and Heit 2011). In addition, these results may be interpreted as being in line with previous studies (Carr et al. 
1994; Vermeer et al. 2000; Verschaffel 1999), revealing that metacognition plays a role in the mastering of new and effortful mathematics.

Within the O-P model, intrinsic motivation (liking the exercises after solving the task) is significantly related as propensity factor to mathematical accuracy in Grade 3, but not to mathematical fluency that was assessed concurrently in January of elementary school. The significant results are in line with the findings of Carr and colleagues (1994), and Kriegbaum and colleagues (2015) who found that motivation contributes to the explained variance of mathematics performance. Additional studies are needed, to examine whether with another operationalization of motivation or more questions to assess the construct, motivation would also have predicted mathematic proficiency significantly in the other grades of elementary school.

Answering the second research question, our findings have revealed different outcomes for concurrent relationships (correlations in January) and for prospective predictions (predictions of measures in January for mathematics in June). Although the crosssectional data revealed that metacognitive postdiction skills are related to mathematical accuracy in all grades (Grades 1-6) and to mathematical fluency in Grades 3 and 4, metacognitive postdiction skills in January do not significantly predict mathematical accuracy or fluency in June. This finding points to the importance of longitudinal studies to examine the sustainability of cross-sectional findings. In addition, the longitudinal data revealed, in line with the O-P model, the impact of previous mathematical accuracy and fluency. In line with studies demonstrating the importance of students' prior mathematics proficiency' (Arefi et al. 2014; Lin and Zabrucky 1998; Nietfield and Schraw 2002), mathematical accuracy in January predicted more than half of the variance of the mathematical accuracy in June. Mathematical fluency in January predicted less than one fifth of the variance in mathematical fluency in June. 
Answering the third research question: poor performers have lower metacognitive accuracy scores and are less intrinsically motivated compared to good performers in all grades. In addition, poor performers overestimate their performances to a higher degree than average performers and good performers in all grades. Our data are also in line with the fact that, from Grade 2 on, the metacognitive estimations are more accurate towards the end of a semester (Lin-Agler et al. 2004; Stolp and Zabrucky 2009), suggesting that children somehow seem to adjust their metacognitive evaluations of their own competence by observing the behaviour of others, or by getting feedback from previous tests (Stolp and Zabrucky 2009; Vanderswalmen et al. 2010).

This study certainly also had some limitations. Firstly, the choice of postdiction represents a restricted assessment of metacognition, which does not include the metacognitive skills employed during task performance. Some might even have doubt about postdictions as relevant indicators of metacognition and (later) mathematics performance. In addition, other measures (Borkowski 1992; Fleming and Lau 2014) such as think aloud protocols might result in different findings (Fleming and Lau 2014). Moreover, the 'accuracy' of postdictions was studied by checking whether the self-reported value corresponded with the occurrence of that value on the criterion test (e.g., Lin and Zabrucky 1998). The accuracy of postdiction was determined, in line with Desoete and Roeyers (2006), based on the comparison of the postdiction and the real performance. The nearer to zero, the more correct the postdiction. However, other calculation procedures and indices are possible as well (Boekaerts and Rozendaal 2010; Desender et al. 2017), such as the ones that have been used in calibration accuracy and metacognitive monitoring studies (Chen 2002; García et al. 1016; Lin et al. 2001; 2002; Lin and Zabrucky 1998; Schraw et al. 2013; 2014) to identify correct and/or incorrect performances. This might have given different study outcomes (Desoete 2008). Moreover, motivation has been operationalized by one single question ('Did you like these exercises'), 
which might be only a small part of intrinsic motivation. More research is also needed to confirm these results in other age groups, including a broader assessment of metacognition and motivation as well as other context variables (such as school and home environment). In addition, poor performers overrate their performance in this study more than other performers; however, this might be an artefact of their lower performance, since there might be, by definition, less chance to make an estimation of one's performance that is lower than one's actual (low) performance.

Nevertheless, the study reveals different concurrent and prospective predictors for mathematical accuracy and fluency. Our findings suggest that metacognition (assessed with a postdiction task) is especially important for mathematical accuracy in elementary school children. Reduced mathematical fluency seems to be related to lower postdictions in Grades 3 and 4. Moreover, the study suggests that intrinsic motivation is especially important for mathematical accuracy tasks (Grade 3) and less for mathematical fluency tasks in elementary school. In addition, poor and good performers seem to differ on metacognitive accuracy and motivation, leading to the practical recommendation to assess and observe these propensity factors. Poor performers seem less motivated, less metacognitive accurate and overestimating their performances to a higher degree than good performing peers in all grades. Finally, this study especially suggests the use of longitudinal designs, including students 'prior mathematics proficiency' in the prediction of mathematics as outcome.

\section{References}

Aesaert, K., \& Denis, J. (2018). Evolutie wiskundeprestaties in het lager onderwijs Trendanalyse van peilingsdata tussen 2002 en 2016. [Evolution of mathematics performances in elementary school children. Trend analysis of testing between 2002 and 2016.]. Paper on the Studie-en ontmoetingsdag voor Vlaamse onderzoekers, opleiders en 
begeleiders van het wiskundeonderwijs aan 3- tot 14-jarigen. 5 June 2018 KULeuven campus groep $\mathrm{T}$.

https://ppw.kuleuven.be/o_en_o/CIPenT/studiedag-wiskundeonderwijs2018/presentaties/k (see also: www.peilingsonderzoek.be)

Arefi, M., Naghibzadeh, M., \& Boloki, A. (2014). The relationship of parental attachment, peer attachment, and academic self-concept to academic achievement of high school students. International Journal of Academic Research, 6, 73-78.

Baten, E., \& Desoete, A. (2018). Mathematical (dis)abilities within the OpportunityPropensity Model: The choice of math test matters. Frontiers in Psychology, Developmental Psychology. doi:10.3389/fpsyg.2018.00667

Baten, E., Praet, M., \& Desoete, A. (2017). The relevance and efficacy of metacognition for instructional design in the domain of mathematics. ZDM Mathematics Education 49, 613-623. doi:10.1007/s11858-017-0851-y.

Baudonck, M., Debusschere, A., Dewulf, B., Samyn, F., Vercaemst, V., \& Desoete, A. (2006). De Kortrijkse Rekentest Revision KRT-R. [The Kortrijk Arithmetic Test Revision KRT-R]. Kortrijk: CAR Overleie

Boekaerts, M., \& Rozendaal, J. S. (2010). Using multiple calibration indices in order to capture the complex picture of what affects students' accuracy of feeling of confidence. Learning and Instruction, 20, 372- 382

Bol, L., \& Hacker, D. J. (2012). Calibration research: Where do we go from here? Frontiers in Psychology, 3, 1-6.

Borkowski, J. G. (1992). Metacognitive theory: A framework for teaching literacy, writing, and math skills. Journal of Learning Disabilities, 25, 253-257.

Borkowski, J. G., \& Thorpe, P .K. (1994). Self-regulation and motivation: A life-span perspective on underachievement. In D. H.. Schunk \& B. J. Zimmerman (Eds.), 
Selfregulation of learning and performance: Issues of educational applications (pp. 45100). Hillsdale, NJ: Erlbaum.

Brown, A. (1987). Metacognition, executive control, self-regulation, and other more mysterious mechanisms. In F. Reiner\& R. Kluwe (Eds.), Metacognition, motivation, and understanding (pp. 65-116). Hillsdale, NJ: Lawrence Erlbaum.

Byrnes, J. P., \& Miller, D. C. (2007). The relative importance of predictors of math and science achievement : An opportunity-propensity analysis. Contemporary Educational Psychology, 32, 599-629. doi:10.1016/j.cedpsych.2006.09.002.

Byrnes, J. P., \& Wasik, B. A. (2009). Factors predictive of mathematics achievement in kindergarten, first and third grades : An opportunity-propensity analysis. Contemporary Educational Psychology, 34, 167-183. doi:10.1016/j.cedpsych.2009.01.002.

Carr, M. Alexander, J., \& Folds-Bennett, T. (1994). Metacognition and mathematics strategy use. Applied Cognitive Psychology, 8, 583-595. doi: 10.1002/acp.2350080605.

Carr, M., \& Jessup, D. L. (1995). Cognitive and metacognitive predictors of mathematics strategy use. Learning and Instruction, 7, 235-247. doi: 10.1016/1041-6080(95)90012.

Chen, P.P. (2002). Exploring the accuracy and predictability of the self-efficacy beliefs of seventh-grade mathematics students. Learning and Individual Differences, 14, 77-90.

Claessens, A., Duncan, G., \& Engel, M. (2009). Kindergarten skills and fifth-grade achievement: Evidence from the ECLS-K. Economics of Education Review, 28, 415427. doi: 10.1016/j.econedurev.2008.09.003.

Claessens, A., \& Engel, M. (2013). How important is where you start? Early mathematics knowledge and later school success. Teachers College Record, 115(6). 060306

Cohen Kadosh, R., \& Dowker, A. (2015). The Oxford handbook of numerical cognition. Oxford: Oxford University Press.

Deary, I. J., Whalley, L. J., Lemmon, H., Crawford, J. R., \& Starr, J. M. (2000). The stability 
of individual differences in mental ability from childhood to old age: Follow-up of the 1932 Scottish mental survey. Intelligence, 28, 49-55. doi: 10.1016/S01602896(99)00031-8.

Deci, E. L., Conell, J., \& Ryan, R. (1989). Self determination in a work organization. Journal of Applied Psychology, 74(4), 580-590.

Deci, E. L., \& Ryan, R. M. (1985). Intrinsic motivation and self-determination in human behavior. Boston, MA: Springer US. http://doi.org/10.1007/978-1-4899-2271-7

Desender, K., Van Opstal, F., \& Van den Bussche, E. (2017). Subjective experience of difficulty depends on multiple cues. Scientific Reports, 7:44222, doi:10.1038/srep44222.

Desoete, A. (2007). Evaluating and improving the mathematics teaching-learning process through metacognition? Electronic Journal of Research in Educational Psychology, 5, $705-730$

Desoete, A. (2008). Multi-method assessment of metacognitive skills in elementary school children: How you test is what you get. Metacognition Learning, 3, 189-206. doi:10.1007/s11409-008-9026-0.

Desoete, A., \& Roeyers, H. (2002). Off-line metacognition. A domain-specific retardation in young children with learning disabilities? Learning Disability Quarterly, 25, 123-139. doi:10.2307/1511279

Desoete, A., \& Roeyers, H. (2006). Metacognitive macroevaluations in mathematical problem solving. Learning and Instruction, 16, 12-25. doi: 10.1016/j.learninstruc.2005.12.003.

Desoete, A., Roeyers, H., \& Buysse, A. (2001) Metacognition and mathematical problem solving in grade 3. Journal of Learning Disabilities, 34, 435-449. doi:

\section{$10.1177 / 002221940103400505$}

Desoete, A., Roeyers, H., \& De Clercq, A. (2003). Can off-line metacognition enhance mathematical problem solving? Journal of Educational Psychology, 95, 188-200. 


\section{doi:10.1037/0022-0663.95.1.188}

Desoete, A., Roeyers, H., \& Huylebroeck, A. (2006). Metacognitive skills in Belgian third grade children (age 8 to 9) with and without mathematical learning disablities. Metacognition Learning, 1, 119-135. doi: 10.1007/s11409-006-81529.

Dowker, A. (2005). Individual differences in arithmetic. Implications for psychology, neuroscience and education. Hove, UK: Psychology Press.

Dowker, A. (2015). Individual differences in arithmetical abilities. The componential nature of arithmetic. In The Oxford Handbook of Mathematical Cognition ( pp. 862-878). Oxford: Medicine UK.

Duncan, G. J., \& Magnuson, K. (2009). The nature and impact of early achievement skills, attention and behavior problems. Paper presented at the Russel Sage Foundation conference on Social Inequality and Educational Outcomes, November 19-20.

Efklides, A. (2001). Metacognitive experiences in problem solving: Metacognition, motivation, and self-regulation. In A. Efklides, J. Kuhl, \& R. M. Sorrentino (Eds.), Trends and prospects in motivation research (pp. 297-323). Dordrecht, The Netherlands: Kluwer.

Efklides, A. (2006). Metacognition and affect: What can metacognitive experiences tell us about the learning process? Educational Research Review, 1, 3-14. doi:10.1016/j.edurev.2005.11.00.

Efklides, A. (2008). Metacognition: Defining its facets and levels of functioning in relation to self-regulation and co-regulation. European Psychologist, 13, 277-287. doi:10.1027/1016-9040.13.4.277.

Efklides, A., \& Sideridis, G. D. (2009). Assessing cognitive failures. European Journal of Psychological Assessment, 25, 69-72.

Erickson, S., \& Heit, E. (2015). Metacognition and confidence: Comparing math to other 
academic subjects. Frontiers in Psychology (6). Article 742.

doi: 10.3389/fpsyg.2015.00742.

Flavell, J. H. (1976). Metacognitive aspects of problem-solving. In L.B. Resnick (Ed.), The nature of intelligence (pp. 231-236). Hillsdale, NJ: Erlbaum.

Flavell, J. H. (1979). Metacognition and cognitive monitoring: A new area of cognitive developmental inquiry. American Psychologist, 34, 906-911

Flavell, J. H. (1987). Speculations about the nature and development of metacognition, In F. E. Weinert \& R. Kluwe (Eds.), Metacognition, motivation and understanding (pp. 2029). Hillsdale, NJ: Erlbaum.

Fleming, S.M., \& Lau, H.C. (2014). How to measure metacognition. Frontier in human neuroscience, 8 , article 443 (1-8). www.frontiersin.org

Fleming, S. M., Donlan, R. J., \& Frith, C. D. (2012). Metacognition: Computation, biology and function. Philosophical Transactions of the Royal Society, 367, 1280-1286. doi:10.1098/rstb.2012.0021.

Furnes, B., \& Norman, E. (2015). Metacognition and reading: Comparing three forms of metacognition in normally developing readers and readers with dyslexia. Dyslexia, 21, 273-284. doi: 10.1002/dys.1501.

García, T., Rodríguez, C., González-Castro, P., González-Pienda, J. A., \& Torrance, M. (2016). Elementary students' metacognitive processes and post-performance calibration on mathematical problem-solving tasks. Metacognition and Learning, 11, 139-170.

Gascoine, L., Higgins, S., \& Wall, K. (2017) The assessment of metacognition in children aged 4-16 years: a systematic review. Review of Education, 5, 3-57. doi:10.1002/rev3.3077

Guay, F., Marsh, H. W., \& Boivin, M. (2003). Academic self-concept and academic achievement: Developmental perspectives on their causal ordering. Journal of 
Educational Psychology, 95, 124-136. doi:10.1037/0022-0663.95.1.124.

Hacker, J. D., Bol, L., Horgan, D. D., \& Rakow, E. A. (2000). Test prediction and performance in a classroom context. Journal of Educational Psychology, 92, 160-170.

Henik, A., Rubinstein, O., \& Ashkenazi, S. (2015). Developmental dyscalculia as a heterogenous Disability. In R. Cohen Kadosh and A. Dowker (Eds.), The Oxford handbook of numerical cognition (pp. 662-667). Oxford, UK: Oxford: University Press.

Koriat, A. (2007). Metacognition and consciousness. In P. D. Zelazo, M. Moscovitch, \& E. Thompson (Eds.), The Cambridge handbook of consciousness (pp. 289-325). Cambridge, UK: Cambridge University Press.

Kriegbaum, K., Jansen, M., \& Spinath, B. (2015). Motivation: A predictor of PISA's mathematical competence beyond intelligence and prior test achievement. Learning and Individual Differences, 43, 140-148. doi: 10.1016/j.lindif.2015.08.026.

Kruger, J. (2002). Unskilled and unaware — but why? A reply to Krueger and Mueller. Journal of Personality and Social psychology, 82, 189-192.

Kruger, J., \& Dunning, D. (1999). Unskilled and unaware of it: How difficulties in recognizing one's own incompetence lead to inflated self-assessments. Journal of Personality and Social Psychology, 77, 1121-1134.

Lin, L., Moore, D., \& Zabrucky, K. M. (2001). An assessment of student's calibration of comprehension and calibration of performance using multiple measures. Reading Psychology, 22, 111-128.

Lin, L., \& Zabrucky, K. (1998). Calibration of comprehension: Research and implications for education and instruction. Contemporary Educational Psychology, 23, 345-391.

Lin, L., Zabrucky, K. M., \& Moore, D. (2002). Effects of text difficulty and adults' age on relative calibration of comprehension. American Journal of Psychology, 115,187-198.

Lucangeli, D., Cornoldi, C, \& Tellarini, M. (1998). Metacognition and learning disabilities in 
mathematics. In T.E. Scruggs \& M.A. Mastropieri (Eds.), Advances in learning and behavioral disabilities (pp. 219-285). Greenwich, UK: JAI Press Inc.

Nelson, T. O. (1996). Consciousness and metacognition. American Psychologist, 51, 102116. doi: 10.1037/0003-066X.51.2.102

Nietfeld, J. L., \& Schraw, G. (2002). The role of knowledge and strategy training on metacognitive monitoring. The Journal of Educational Research, 95, 131-142.

Orsini, C., Evans, P., \& Jerez, O. (2015). How to encourage intrinsic motivation in the clinical teaching environment? A systematic review from the self-determination theory. Journal of Educational Evaluation for Health Professions, 12, 8. http://doi.org/10.3352/jeehp.2015.12.8

Oszoy, G. (2011). An investigation of the relationship between metacognition and mathematics achievement. Asia Pacific Education Review, 12, 227-235. doi: $10.1007 / \mathrm{s} 12564-010-9129-6$.

Ozcan, Z.C. (2014). Assessment of metacognition in mathematics: Which one of two methods is a better predictor of mathematics achievement? International Online Journal of Educational Studies, 6(1), 49-57. doi: 10.15345/iojes.2014.01.006.

Perfect, T., \& Schwartz, B. (2002). Applied metacognition. Cambridge, UK: Cambridge University Press.

Pressley, M. (2000). Development of grounded theories of complex cognitive processing: exhaustive within- and between study analyses of thinking-aloud data. In G. Schraw, \& J. C. Impara (Eds.), Issues in the measurement of metacognition (pp. 262-296). Lincoln, NE: Buros Institute of Mental Measurements.

Pieters, S., Roeyers, H., Rosseel, Y., Van Waelvelde, H., \& Desoete, A. (2015). Identifying subtypes among children with developmental coordination disorder and mathematical learning disabilities, using model-based clustering. doi: 10.1177/0022219413491288. 
Ryan, R. M., \& Deci, E. L. (2017). Self-determination theory. Basic psychological needs in motivation, development and wellness. New York, NY: Guilford Press.

Schraw, G., \& Graham, T. (1997). Helping gifted students develop metacognitive awareness. Roeper Review, 20, 4-8.

Schraw, G., Potenza, M. T., \& Nebelsick-Gullet, L. (1993). Constraints on the calibration of performance. Contemporary Educational Psychology, 18, 455-463.

Schneider, W., \& Artelt, C. (2010). Metacognition and mathematics education. ZDM Mathematics Education, 42, 149-161. doi:10.1007/s11858-010-0240-2

Schneider, W., \& Löffler, E. (2016). The development of metacognitive knowledge in children and adolescents. In J. Dunlosky \& S. K. Tauber (Eds.), The Oxford handbook of metamemory (pp. 491-518). New York, NY: Oxford University Press.

Schraw, G., Kuch, F., \& Gutierrez, A. P. (2013). Measure for measure: Calibrating ten commonly used calibration scores. Learning and Instruction, 24, 48-57.

Schraw, G., Kuch, F., Gutierrez, A. P., \& Richmond, A. S. (2014). Exploring a three-level model of calibration accuracy. Journal of Educational Psychology, 106, 1192-1202.

Schwarz, N. (1999). Self-reports. How questions shape the answers. American Psychologist, $54,93-105$.

Schwartz, B., \& Metcalfe, J. (1992). Cue familiarity but not target retrievability enhances feeling-of-knowing judgments. Journal of Experimental Psychology: Learning, Memory and Cognition, 18, 1074-1083.

Seaton, M., Marsh, H. W., Parker, P. D., Craven, R. G., \& Yeung, A. S. (2015). The Reciprocal Effects Model revisited. Gifted. Child Quarterly, 59, 143-156. doi:10.1177/0016986215583870.

Siemann, J., \& Petermann, F. (2018). Evaluation of the Triple Code Model of numerical processing - Reviewing past neuroimaging and clinical findings. Research in Developmental Disabilities, 72, 106-117. doi:10.1016/j.ridd.2017.11.001. 
Sperling, R. A., Howard, B. C., Miller, L. A., \& Murphy, C. (2002). Measures of children's knowledge and regulation of cognition. Contemporary Educational Psychology, 27, 5179.

Spinath, B., Spinath, F. M., Harlaar, N., \& Plomin, R. (2006). Predicting school achievement from general cognitive ability, self-perceived ability, and intrinsic value. Intelligence, 34 , 363-374. doi: 10.1016/j.intell.2005.11.004.

Stolp, S., \& Zabrucky, K.M. (2009) Contributions of metacognitive and self regulated learning theories to investigations of calibration of comprehension. International Electronic Journal of Elementary Education, 2 (1), 7-31, October, 2009.

Tarricone, P. (2011). The taxonomy of metacognition. Hove, East Sussex: Psychology Press.

Taylor, G., Jungert, T., Mageau, G. A., Schattke, K., Dedic, H., Rosenfield, S., \& Koestner, R. (2014). A self-determination theory approach to predicting school achievement over time: The unique role of Intrinsic Motivation. Contemporary Educational Psychology, 39, 342-358. doi: 10.1016/j.cedpsych.2014.08.002

Townsend, C.L., \& Heit, E. (2011). Jugdments of learning and improvement. Memory \& Cognition, 39, 204-216. doi: 10.3758/s13421-010-0019-2

Vanderswalmen, R., Vrijders, J., \& Desoete, A. (2010). Metacognition and spelling performance in college students. In Efklides, A., \& Misailidi, P. (Eds.). Trends and prospects in metacognition research (pp. 367-394). New York: Springer.

Vansteenkiste, M., Sierens, E., Soenens, B., Luyckx, K., \& Lens, W. (2009). Motivational profiles from a self-determination perspective: The quality of motivation matters. Journal of Educational Psychology, 101, 671-688. http://doi.org/10.1037/a0015083

Veenman, M. V. J. (2011). Alternative assessment of strategy use with self-report instruments: A discussion. Metacognition and Learning, 6, 205-211. doi:10.1007/s11409-011-9080-x. 
Veenman, M. V. J., Van Hout-Wolters, B. H. A. M., \& Afflerbach, P. (2006). Metacognition and learning: Conceptual and methodological considerations. Metacognition and Learning, 1, 3-14.

Vermeer, H. J., Boekaerts, M., \& Seegers, G. (2000). Motivational and gender differences: Sixth-grade students' mathematical problem-solving behavior. Journal of Educational Psychology, 92, 308-315. doi: 10.1037/0022-0663.92.2.308

Verschaffel, L. (1999). Realistic mathematical modelling and problem solving in the upper elementary school: Analysis and improvement. In J. H. M. Hamers, J. E. H. Van Luit, \& B. Csapo (Eds.), Teaching and learning thinking skills. Contexts of learning (pp. 215240). Lisse: Swets \& Zeitlinger.

Wang, A. H., Shen, F., \& Byrnes, J. P. (2013). Does the Opportunity-Propensity Framework predict the early mathematics skills of low-income pre-kindergarten children? Contemporary Educational Psychology, 38, 259-270. doi: 10.1016/j.cedpsych.2013.04.004 